\title{
Reactivity of Nellore Cows in Corral Handling and Containment Chute
}

\author{
Teresinha Inês Assumpção \\ Gustavo Guerino Macedo \\ Laboratory of Animal Reproduction \\ Federal University of Uberlandia \\ Uberlandia, MG - Brazil \\ Camylla Pedrosa Monteiro \\ Master student \\ Sao Paulo University \\ Pirassununga, SP - Brazil \\ Isabel Cristina Ferreira \\ Research of EMBRAPA Cerrados \\ Planaltina, DF - Brazil \\ Thaís Mendes Sanches Cavalero \\ Master student \\ Sao Paulo State University \\ Botucatu, SP - Brazil \\ Murillo Figueiredo Dourado \\ Veterinary Doctor \\ Mirassol, SP - Brazil
}

\begin{abstract}
This study aimed to evaluate the effect of the frequency of successive handlings in corral during animal restraint regarding herdsperson attitude and the reactivity/flight speed of animals, presence of hair whorls, the association between these characteristics and animal temperament. Fifty 30-40 months-old Nellore cows were divided in two groups: 1) with six handlings and 2) with two handlings. Animal reactivity during containment handling was evaluated through visual scores, presence or absence of hair whorls and their location on the face, as well as herdsperson attitude towards the animals. It was observed that among the management systems, herdsperson attitude, chute movement, body posture, tension, reactivity, and flight speed were influenced by the management systems, with less animals reactivity. No associations were found between presence, type, and size of hair whorl and animal reactivity and flight speed, as well as between successive handlings and the presence of kicking, mooing, and feces.
\end{abstract}

Keywords: Animal reactivity, Bos indicus, cattle, handling treatments, temperament.

\section{Introduction}

Brazil has a cattle herd of approximately 219.18 million animals (DEPEC, 2017), and the Nellore breed represents $90 \%$ of the Bos indicus animals. It is a breed of high rusticity and climatic adaptation, high reproductive longevity and maternal ability, but presents a more arduous temperament when bred extensively or poorly handled (Albuquerque et al., 2007). The stress-inducing stimulus to the production animal causes numerous losses, such as drop in food consumption (Voisinet et al., 1997), loss of meat quality, employee and animal injuries, low productive (Paranhos da Costa et al., 2002) and reproductive (Macedo et al., 2011) rates, and increased handling cost and time (Burrow, 1997). Animal temperament is measured by its behavioral response to human stimulus and its reactivity can be used to indicate how easy it is to approach the animal, guide it, orient it, and work with it (Maffei et al., 2006). Animal temperament can be evaluated by animal containment tests (weighting scale or chute reactivity) or tests without containment (distance and flight speed test) (Costa e Silva et al., 2010). 
It can also be evaluated by the presence or absence of hair whorls, which can be parameters to assist producers when selecting cattle (Grandin, 1999; Martins et al., 2009). The flight speed test evaluates the speed it takes the cattle to exit the containment chute or weighting scale after the gate is opened. Animals that take longer to leave have a better temperament (Sant'anna and Paranhos da Costa, 2010). The distance test evaluates the minimum distance the bovine allows an observer to approach it before it moves, detecting the repulsion of the animals against the presence of a human being (Peixoto et al., 2011). In this sense, the relationship between herdsperson and cattle can be altered during the handling when the temperament of the animals is more wild and stressed (individual characteristic), directly influencing the gains of animal productivity. Thus, the objectives of this study were to evaluate the effect of frequent successive handlings in corral during animal restraint, regarding the attitude of the herdsperson and the reactivity and flight speed of the animals, and if these characteristics were associated with each other and with the presence of hair whorls and temperament of the animals.

\section{Materials and Methods}

The experiment was conducted at Capim Branco Experimental Farm, Federal University of Uberlandia, Uberlandia, State of Minas Gerais, Brazil. This farm is located at latitude $18^{\circ} 55^{\prime} 23^{\prime \prime S}$, longitude $48^{\circ} 17^{\prime} 19^{\prime \prime} \mathrm{W}$. The average annual rainfall is of $1500 \mathrm{~mm}$, with average annual temperature of $22.3^{\circ} \mathrm{C}$, relative humidity of around $71 \%$, and a tropical climate. 50 Nellore cows (30-40 months-old) were handled in a corral that meets animal welfare standards. This research was authorized by the Ethics Committee on the Use of Animals of the Federal University of Uberlandia, protocol number 025/2014. The experimental setup was completely random, with measures repeated over time. The animals were randomly assigned to two different treatments and submitted to two different intervals of handling. 25 cows were assigned to Treatment 1 (TREAT 1), where they were handled every seven days for six consecutive weeks. 25 cows were assigned to treatment 2 (TREAT 2), where they were handled only twice at intervals of 30 days between one observation and the other. The animals of the two groups were submitted to the routine handling of the farm during containment in the chute, so that it would be possible to evaluate the reactivity/temperament of the animals.

The reactivity evaluation of the animals was based and adapted from the methodology described by Piovesan (1998). To assess the reactivity of cattle it was observed reactivity in containment chute; presence, location, size, and type of hair swirl; flight speed; and the attitude of the herdsperson towards the animals during handling. One week before performing the reactivity evaluations, the animals were submitted individually to a containment chute and were evaluated regarding the presence, type (curvilinear/rectilinear), size (large/small), and location of facial hair whorl. The facial hair whorl height was measured drawing an imaginary line above the eye line of the animal. The hair whorl center was the reference point to determine the type of whorl (Grandin et al., 1995). The location, size and type of swirls were classified as follows:

- Location and size:

1. Large hair whorl above the forehead; 2. Small hair whorl above the forehead; 3. Large hair whorl above the eye line; 4. Small hair whorl above the eye line; and 5. Hair whorl in the eye line.

- Type of hair whorl:

\section{Rectilinear; and 2. Curvilinear}

It was observed and taken note of how the herdsperson conducted the cattle to the lateral corridor and to the chute. The use of instruments to conduct the animals (sting, stick, flag), voice tone (presence or not of shouts and medium voice tone), and speed (slow, average, fast) during handling was also observed. The herdsperson handling was classified as: violent (use of stings, shouting, and fast speed); moderate (use of stick, average voice tone, and speed) and good (use of flag, no shouting, and slow speed) (Rueda, 2009). The reactivity and flight speed measurement was performed by two previously trained observers. The reactivity test in containment chute, or agitation score, was performed with composite score (Rueda, 2009), that is, the cows entered the containment chute and after 10 seconds it was taken note of how much the animal moved in the chute, breathing audibility, tension, presence/absence of vocalization, presence/absence of feces, and presence/absence of kicking. Scores were assigned to each of these behaviors, as described below:

- Movement in the chute (MC): 1 . little movement inside the chute, still most of the time; 2 . more active animal, not remaining in the same position for more than a few seconds; 3 . frequent, vigorous, and abrupt movement inside the chute; and 4. frequent, strong, and continuous movement inside the chute. 
- Body posture (BP): 1. standing: the animal remains standing on all four limbs; 2 . kneeling: at some point the animal leans on the hind limbs or hocks; 3. lying: the animal remains lying on the chute.

- Breathing: 1. non-audible breathing; 2. audible and deep breathing; and 3. snorting or snoring.

- Tension: 1. relaxed animal (regular muscle tone, no abrupt movements of tail and/or head and neck, sclerotic membrane is not apparent); 2. slightly tense animal (regular muscle tone with abrupt movements of tail and/or head and neck); 3. tense animal (tense muscle tone with abrupt movements of the tail and/or head and neck, sclerotic membrane apparent or not); and 4. very tense animal (muscular tremors and sclerotic membrane apparent or not).

- Vocalization, kicking, and feces: binomially evaluated. Based on the records of the above categories a new variable was defined the chute reactivity of where it was composed of five classes arranged in ascending order, as described below:

\begin{tabular}{lccccccc}
\hline Movement in the chute & $\begin{array}{c}\text { Body } \\
\text { posture }\end{array}$ & Tension & Breathing & Kicking & Feces & Mooing \\
\hline Calm & 1 & 1 & 1 & 1 & 0 & 0 & 0 \\
Active & 2 & 1 & $1 / 2$ & $1 / 2$ & $0 / 1$ & $0 / 1$ & $0 / 1$ \\
Restless & $2 / 3$ & $1 / 2$ & $2 / 3$ & $2 / 3$ & $0 / 1$ & $0 / 1$ & $0 / 1$ \\
Wild & 4 & $1 / 2 / 3$ & 3 & $2 / 3$ & $0 / 1$ & $0 / 1$ & $0 / 1$ \\
Still & 1 & 1 & $\begin{array}{c}\text { Muscular } \\
\text { tremor }\end{array}$ & 1 & 0 & $0 / 1$ & $0 / 1$ \\
\hline
\end{tabular}

Soon after the handling in containment chute was over, the flight speed test was performed, in which it was considered that the most reactive animals tend to leave the chute in higher speed. To measure it, the timer was triggered to evaluate the time it took the animals to walk 3 meters immediately after leaving the chute. According to the average of the animals, a speed scale $(\mathrm{m} / \mathrm{s})$ was built classifying the reactivities of the animals in three classes: 1 - calm: 0.36 to $0.79(\mathrm{~m} / \mathrm{s}), 2$ - reactive: 0.8 to $1.23(\mathrm{~m} / \mathrm{s})$, and 3 - very reactive: 1.24 to $1.67(\mathrm{~m} / \mathrm{s})$ (Rueda, 2009).

The data were evaluated by variance analysis, followed by the Mann-Whitney test (non-parametric analysis), where the relationship between handling frequency and the attitude of the herdsperson, chute movement, body posture, breathing, tension, reactivity, and flight speed of females in Treatments 1 (handled 6 times) and Treatment 2 (handled 2 times).

The Spearman'rank correlation and coefficient assessed the relationship between the characteristics: herdsperson's attitude scores, chute movement, body posture, breathing, tension, reactivity, and flight speed. The location, size, and type of hair whorl analysis and its relation with the reactivity and flight speed of the animals were made by non-parametric analysis of variance using the Kruskal-Wallis test. The Chi-square test analyzed the effect of successive handling with the presence of kicking, mooing, and feces. The significance level was $\mathrm{P}<0.05$.

\section{Results}

Table 1 shows the means of the relationship between handling frequency and herdsperson attitude, chute movement, body posture, breathing, tension, reactivity, and flight speed of the females in both treatments.

Table 1. Effect of treatment (TREAT 1 - a lot of handling and TREAT 2- little handling) on the attitude of the herdsperson and the Nellore females $(\mathrm{P}<0.05)$.

\begin{tabular}{lccc}
\hline & TREAT 1 & TREAT 2 & P \\
\hline Herdsperson attitude & 2.16 & 2.00 & 0.042 \\
Chute movement & 1.84 & 2.44 & 0.011 \\
Body posture & 1.00 & 1.16 & 0.038 \\
Breathing & 1.40 & 1.60 & 0.132 \\
Tension & 1.84 & 2.40 & 0.012 \\
Reactivity & 1.84 & 2.44 & 0.011 \\
Flight speed & 1.72 & 2.04 & 0.052 \\
\hline
\end{tabular}


Table 2 shows the correlations among the evaluated characteristics: herdsperson attitude scores, chute movement, body posture, breathing, tension, reactivity, and flight speed.

Table 2. Correlations between the attitude scores of the herdsperson and the reactivity characteristics of the Nellore females evaluated in the containment chute $(\mathrm{P}<0.05)$.

\begin{tabular}{lccccccc}
\hline & HA & CM & BP & Breathing & Tension & Reactivity & FS \\
\hline HA & - & 0.209 & -0.062 & 0.184 & 0.217 & 0.209 & 0.367 \\
CM & & - & 0.360 & 0.777 & 0.938 & 0.947 & 0.492 \\
BP & & & - & 0.386 & 0.310 & 0.364 & 0.168 \\
Breathing & & & & - & 0.761 & 0.772 & 0.398 \\
Tension & & & & - & 0.938 & 0.479 \\
Reactivity & & & & & & - & 0.492 \\
FS & & & & & & - \\
\hline
\end{tabular}

$\mathrm{HA}$ - herdsperson attitude, CM - chute movement, BP - body posture, FS - flight speed.

The variance analysis that evaluated the location, size, and type of hair whorl and its relation with the reactivity and flight speed of the animals did not show any significant results, as shown in table 3.

The analysis of the effect of successive handlings with the presence of kicking, mooing, and feces did not present a significant statistic difference for the three characteristics $(P=0.312)$. During this research, the occurrence of these variables was relatively low, possibly why statistical difference was not observed.

Table 3. Multiple comparisons between hair whorl and reactivity and flight speed of Nellore females.

\begin{tabular}{lcccc}
\hline & \multicolumn{2}{c}{ Location and size } & \multicolumn{2}{c}{ Type of whorl } \\
\hline & Calculated & Tabulated & Calculated & Tabulated \\
Reactivity & 3.64 & 9.49 & 1.54 & 5.99 \\
FS & 3.10 & 9.49 & 1.90 & 5.99 \\
\hline
\end{tabular}

\section{Discussion}

A similar result was obtained by Rueda (Rueda, 2009), who verified that during successive handlings of a protocol of artificial insemination at a fixed time there was a decrease in the reactivity of bovine females. This was also verified by Macedo et al. (Macedo et al., 2011) in Nellore females in embryo production handling, where the animals presented lower levels of cortisol in the blood, resulting in lower animal stress. The animals from TREAT 1 had lower means of chute movement, body posture, tension, reactivity, and flight speed. This indicates that a higher frequency of handling leads to a lower mean reactivity of the animals. Except for breathing, the results found in the present study for the variables of flight speed and reactivity composed scores suggest that after a first contact with the used management system, in this case the handling in containment chute, the animals demonstrate habituation to the procedure.

These results are similar to those observed by Paranhos da Costa et al. (Paranhos da Costa et al., 2002), who affirm that the calmness degree of the animal is due to the intensity of the handling and the time it takes. Chiquitelli Neto et al. (Chiquitelli Neto et al., 2011) observed reduction in animal reactivity due to familiarity with the place and with the herds people in the handling routine. Silva et al. (Silva et al., 2009) also verified that the reaction of the animals to more intense contact with the herdsperson is made easier or more difficult according to the quality of the human handling and the cattle temperament. In the present study, changes in the behavior of the herds people were verified when they handled the animals more frequently (table 1). Such event may have occurred due to fatigue and stress of the herds people during constant handling of the animals. According to table 2, a low but significant correlation was found between the herdsperson attitude and the flight speed $(\mathrm{r}=0.36)$. Correlations between herdsperson and chute movement $(r=0.20)$, body posture $(r=-0.06)$, breathing $(r=0.18)$, tension $(r=0.21)$, and reactivity $(r=0.20)$ were not significant. Macedo et al. (Macedo et al., 2011) affirm that the voice and the stimulus of the herdsperson are directly related to the animal accidents in corral and that cattle receiving negative stimuli in their interaction with man present higher concentrations of cortisol (high stress). This result is probably related to the way the herds people approached the animals, being classified as moderate to good in most of the analysis during the study. Correlations were verified between chute movement and body posture $(r=0.36)$, breathing $(r=0.77)$, tension $(r=0.93)$, reactivity $(r=0.94)$, and flight speed $(r=0.49)$. 
The results were similar to those of Aguilar (Aguilar, 2007), who also verified positive correlations between chute movement, reactivity, tension, and breathing in Nellore embryo donors. Movement in the chute is a viable and useful tool to evaluate the temperament of cattle, when one wishes to perform the reactivity composite test in containment chute.

Correlation between body posture with breathing $(\mathrm{r}=0.38)$ and reactivity $(\mathrm{r}=0.36)$ was low but significant, different from body posture with tension $(r=0.31)$ and flight speed $(r=0.16)$, where a correlation could not be found. Differently from what was found in this research, Silva et al. (Silva et al., 2009) did not observe correlation between body posture and breathing. The low correlation with the body posture variable indicates that more studies are needed to prove the efficiency of this variable in the evaluation of Nellore cattle temperament. The correlation between breathing with tension $(r=0.76)$, reactivity $(r=0.77)$ and flight speed $(r=0.47)$ were significant mainly in the variables of the composite score of reactivity in containment chute, as well as between the reactivity and flight speed tests $(\mathrm{r}=0.49)$. This was expected, since both tests evaluated cattle temperament. Curley et al. (Curley et al., 2004) and Barbosa Silveira et al. (Barbosa Silveira et al., 2008) also verified the same correlations found in this study. On the other hand, Boivin et al. (Boivin et al., 1992), Grandin (Grandin, 1993), and Aguilar (Aguilar, 2007) did not find significant associations or they were very low between flight speed and reactivity in containment chute, chute movement, breathing, and tension. According to Piovesan (Piovesan, 1998), this is because the measures represent different temperament characteristics, with the score being composed of reactivity related to calmness and the flight speed being linked to animal docility. Barbosa Silveira et al. (Barbosa Silveira et al., 2008) also made the same observation and showed that the ethnological group significantly influenced animal temperament, where the Bos indicus animals presented higher reactivity than the Bos taurus animals or their crosses.

In the present study, the variance analysis did not show significant results between presence, type, and size of hair whorl with reactivity and flight speed (table 3). Our results differ from those verified by Grandin et al. (Grandin et al., 1995) and Martins et al. (Martins et al., 2009), who observed that bulls that had a whorl above the eye line had a more excitable and aggressive temperament, indicating that the height and presence of the hair whorl on the frontal face of cattle have a significant effect on docility frequency or aggressiveness. The chi-square analysis did not show statistical difference between successive handlings and the presence of kicking, mooing, and feces. Regarding defecation, although no significance was observed, it was verified that most of the defecations occurred early, in the syringe and not in the containment chute, and animals that did it were more reactive and less handled, which was also observed by Silva et al. (Silva et al., 2009) when evaluating the reactivity of Nellore bulls.

\section{Conclusion}

We can conclude that the effect of time interval between chute handling in well managed systems has positive effects on reactivity in Nellore cattle, showing that handling animals at a shorter interval is a good strategy. Variables such as chute movement, body posture, breathing, tension, reactivity, and flight speed are appropriate measures to classify animals for their chute reactivity. More studies with a higher number of animals with varied ages and different herds are required to verify the association between reactivity composite score and flight speed with the evaluation of hair whorl in Nellore cattle.

This research did not receive any specific grant from funding agencies in the public, commercial, or not-for-profit sectors.

\section{References}

Aguilar, N. M. A. (2007). Avaliação da reatividade de bovinos de corte e sua relação com caracteres reprodutivos e produtivos. [Online] Available: https://repositorio.unesp.br/handle/11449/91612 ( October 20, 2017).

Albuquerque, L. G., Mercadante, M. E. Z., Eler J. P. (2007). Aspectos da seleção de Bos indicus para produção de carne: revisão bibliográfica. Boletim da Indústria Animal, 64, 339-348.

Barbosa Silveira, I. D., Fischer, V., Soares , G. J. D. (2008). Efeito do grupo etnológico no temperamento de novilhos mantidos em condições extensivas. Archives de Zootecnia, 57, 123-129.

Boivin, X., Le Neindre, P., Chupin, J., Garel, J.P., Trillat, G. (1992). Influence of breed and early management on ease of handling and open-field behavior of cattle. Applied Animal Behavior Science, 32, 313-323. 
Burrow, H. M. (1997). Measurements of temperament and their relationships with performance traits of beef cattle. Animal Breeding Abstract, 65, 477-495.

Chiquitelli Neto, M., Donofre, A. C., Marson, F. L., Puoli Filho, J. N. P., Lima, L. M. B., Oliveira, R. A. R., Brandi, R. A., Nakanish, E. Y. (2011). Efeito do intervalo de tempo entre os dias de manejos sobre a reatividade em bovinos de corte. Revista Científica Eletrônica de Medicina Veterinária, 16, 1-9.

Costa e Silva, E. V., Rueda, P. M., Carneiro, P. C. P. B. (2010). Estratégias para avaliar bem-estar animais em animais em reprodução. Ciência Veterinária Tropical, 13, 20-28.

Curley, K. O., Neuendorff, D. A., Lewis, A. W., Cleere, J. J., Randel, R. D. (2004). Evaluation of temperament and stress physiology may be useful in breeding programs. Beef cattle research in Texas publication. [Online] Available: http://animalscience.tamu.edu/livestock-species/beef/ research (October 7, 2017).

DEPEC (Departamento de Pesquisas e Estudos Econômicos), Carne Bovina, 2017. [Online] Available: http://www.economiaemdia.com.br (October 15, 2017).

Grandin, T. (1993). Behavioral agitation during handling of cattle is persistent over time. Applied Animal Behavior Science, 36, 1-9.

Grandin, T. (1999). Acclimate, don't agitate: Cattle and horses with excitable temperaments must be introduced gradually to new experiences. Beef, 6, 14-16.

Grandin, T., Deesing, M. J., Struthers, J. J., Swinker, A. M. (1995). Cattle with hair whorl patterns above the eyes are more behaviorally agited during restrait. Applied Animal Behavior Science, 46, 117-123.

Macedo, G. G., Zúccari, C. E. S. N., Abreu, U. G. P., Negrão, J. A., Costa e Silva E. V. (2011). Human-animal interaction, stress and embryo production in Bos indicus donors under tropical conditions. Tropical Animal Health Production, 43, 1175-1182.

Maffei, W. E., Bergmann, J. A. G., Pinotti, M. (2006). Reatividade em ambiente de contenção móvel: uma nova metodologia para avaliar o temperamento bovino. Arquivo Brasileiro Medicina Veterinária e Zootecnia, $58,1123-1231$.

Martins, C. E. N., Quadros, S. A. F., Trindade, J. P. P., Quadros, F. L. F., Costa, J. H. C., Raduenz, G. (2009). Forma e função em vacas Braford: o exterior como indicativo de desempenho e temperamento. Archivos de Zootecnia, 58, 423-433.

Paranhos da Costa, M. J. R., Costa e Silva, E. V., Chiquitelli Neto, M., Rosa, M. S. (2002). Contribuição dos estudos de comportamento de bovinos para implementação de programas de qualidade de carne. 2002. Proceedings of 20th Encontro Anual de Etologia; Sept 25-28; Natal, Brasil.

Peixoto, M. G. C. D., Pires, M. F. A., Pereira, M. C., Carvalho, M. R. S., Ribeiro, G. C., Brito, L. F., Verneque, R. S., Bergmann, J. A. G. (2011). Integrando o temperamento às características de importância para o melhoramento de bovinos de leite: resultados de um estudo com fêmeas Guzerá. Revista Brasileira de Zootecnia, 40, 26-37.

Piovezan, U. (1998). Análise de fatores genéticos e ambientais na reatividade de quatro raças de bovinos de corte ao manejo. [Online] Available: http://www.iz.sp.gov.br/publica.php?id=126 (October 20, 2017).

Rueda, P. M. Alterações comportamentais e hematológicas em vacas Nelore submetidas à protocolo de inseminação artificial em tempo fixo 2009. [Online] Available:

http://repositorio.cbc.ufms.br:8080/jspui/handle/123456789/963 (October 13, 2017).

Sant'Anna, A. C., Paranhos da Costa, M. J. R. (2010). Comportamento como indicador do temperamento de bovinos e aplicações na seleção genética. 2010. Proceedings of $28^{\text {th }}$ Encontro Anual de Etologia; Nov 1215; Alfenas, Brasil.

Silva, A. G. F., Rueda, P. M., Araújo, D. G., Zúccari, C. E. N., Costa e Silva E. V. (2009). Reatividade de tourinhos Nelore após manejos sucessivos. 2009. Proceedings of $27^{\text {th }}$ Encontro Anual de Etologia; Nov 12-15; Bonito, Brasil.

Voisinet, B. D., Grandin, T., Tatum, S. F., O'Connor, S. F., Struthers, J. J. (1997). Feedlot cattle with calm temperaments have higher average daily gains than cattle with excitable temperaments. Journal Animal Science, 75, 892-896. 